\title{
AN INVESTIGATION OF CONTACT PATH AND KINEMATIC ERROR OF FACE- GEAR DRIVES
}

Tsang-Dong Chung

Associate Professor, Department of Mechanical Engineering, Nanya Institute of Technology, Tauyan, Taiwan, R.O.C., inerchung@yahoo.com.tw

Yun-Yuan Chang

Research, Mechanical Industry Research Laboratories, Industrial Technology Research Institute (ITIR), Hsinchu, Taiwan, R.O.C.

Follow this and additional works at: https://jmstt.ntou.edu.tw/journal

Part of the Mechanical Engineering Commons

\section{Recommended Citation}

Chung, Tsang-Dong and Chang, Yun-Yuan (2005) "AN INVESTIGATION OF CONTACT PATH AND KINEMATIC ERROR OF FACE-GEAR DRIVES," Journal of Marine Science and Technology. Vol. 13: Iss. 2, Article 4.

DOI: $10.51400 / 2709-6998.2109$

Available at: https://jmstt.ntou.edu.tw/journal/vol13/iss2/4

This Research Article is brought to you for free and open access by Journal of Marine Science and Technology. It has been accepted for inclusion in Journal of Marine Science and Technology by an authorized editor of Journal of Marine Science and Technology. 


\title{
AN INVESTIGATION OF CONTACT PATH AND KINEMATIC ERROR OF FACE-GEAR DRIVES
}

\author{
Tsang-Dong Chung* and Yun-Yuan Chang**
}

Key words: face-gear, tooth contact analysis, transmission error.

\section{ABSTRACT}

Based on the face-gear generation process, the analytical geometry of face-gear drive with its mathematical model for tooth contact analysis of face-gear and spur pinion meshing was derived. In this paper, contact path and transmission error due to assembly misalignment are analyzed by using the proposed mathematical model and the tooth contact analysis. The effects of assembly error along the axis of face-gear, misalignment of crossed and angular displacement between axes of a spur pinion and a face-gear are all investigated. The results are illustrated by several examples.

\section{INTRODUCTION}

Face-gear has been widely used in low power transmission applications. An important application of a face-gear drive is in the helicopter transmission [3]. It uses the idea of the split torque that appears to be significant where a spur pinion drives two face-gears to provide an accurate division of power. This mechanism greatly reduces the size and cost compared to conventional design.

Until now, few research activities about manufacturing and design of face-gear drive were reported. Buckingham [1] and Dudley [2] provided a brief description of face-gear drives. The research about facegear drives was initiated by McDonnell Douglas Helicopter Co.. Important investigations of face-gear drives were performed by Litvin et al. [9, 10] and Litvin [3, 4].

Paper Submitted 11/05/04, Accepted 12/31/04. Author for Correspondence: Tsang-Dong Chung. E-mail: inerchung@yahoo.com.tw.

*Associate Professor, Department of Mechanical Engineering, Nanya Institute of Technology, Tauyan, Taiwan, R.O.C.

**Research, Mechanical Industry Research Laboratories, Industrial Technology Research Institute (ITIR), Hsinchu, Taiwan, R.O.C.
Litvin and Egelja [5] investigated computerized generation, localization of bearing contact and simulation of meshing and contact of an orthogonal offset face-gear drive with a spur involute pinion. Two versions of geometry of face-gear drives were investigated in [7] that provides a new method for generation of facegears by application of a grinding worm, and tooth contact analysis and stress analysis had been performed. Litvin et al. [6] proposed and investigated new types of face-gear drives for application in transmissions, particularly, in helicopter transmissions. Litvin et al. [8] developed an analytical approach for a face-gear drive with a spur involute pinion.

In this paper, numerical analysis on contact path and transmission errors induced by assembly error along axis of face-gear direction and misalignment of crossed and angular displacement between axes of face-gear and pinion is presented. It limits the results to the case of face-gear drive with the intersected axes rotation. The contents of this paper cover the following topics: (1) Generation process of face-gear by shaper with computer simulation, (2) Kinematics of face-gear meshing with spur pinion simulation, (3) Tooth contact analysis, (4) Numerical results and discussion, and (5) Conclusions.

\section{MATHEMATIC MODEL}

\section{Generation process of face-gear by shaper with com- puter simulation}

The generation process of face-gear by a shaper is illustrated in Figure 1(a). The face-gear and shaper rotates about its own axis with angular velocities, $\omega_{2}$ and $\omega_{s}$, respectively. Both axes intersect at point, $O$. Coordinate systems, $S_{s}\left(x_{s}, y_{s}, z_{s}\right), S_{2}\left(x_{2}, y_{2}, z_{2}\right)$ and $S_{m}$ $\left(x_{m}, y_{m}, z_{m}\right)$ are respectively fixed on the shaper, facegear, and the frame of cutting machine.

The face-gear tooth surface, $\Sigma_{2}$, is determined as the envelope to the family of shaper surface, $\Sigma_{s}$, that is represented in coordinate system, $S_{s}$. In Figure 1(b), 
shaper surface, $\Sigma_{s}$, and its position vector, $\mathbf{r}_{\mathbf{s}}$, are related by

$$
\mathbf{r}_{\mathbf{s}}\left(u_{s}, \theta_{s}\right)=\left[\begin{array}{c}
r_{b s}\left[\sin \left(\theta_{o s}+\theta_{s}\right)-\theta_{s} \cos \left(\theta_{o s}+\theta_{s}\right)\right] \\
-r_{b s}\left[\cos \left(\theta_{o s}+\theta_{s}\right)+\theta_{s} \sin \left(\theta_{o s}+\theta_{s}\right)\right] \\
u_{s} \\
1
\end{array}\right]
$$

where $u_{s}$ and $\theta_{s}$ are surface coordinates of the shaper, $r_{b s}$ is the base circle radius of the shaper, $\theta_{\text {os }}$ determines the width of the shaper space on the base circle and can be represented by the equation

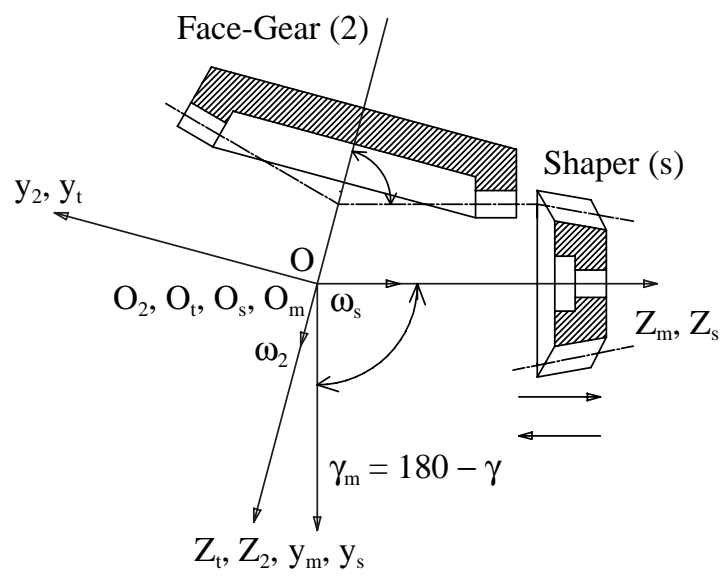

(a)

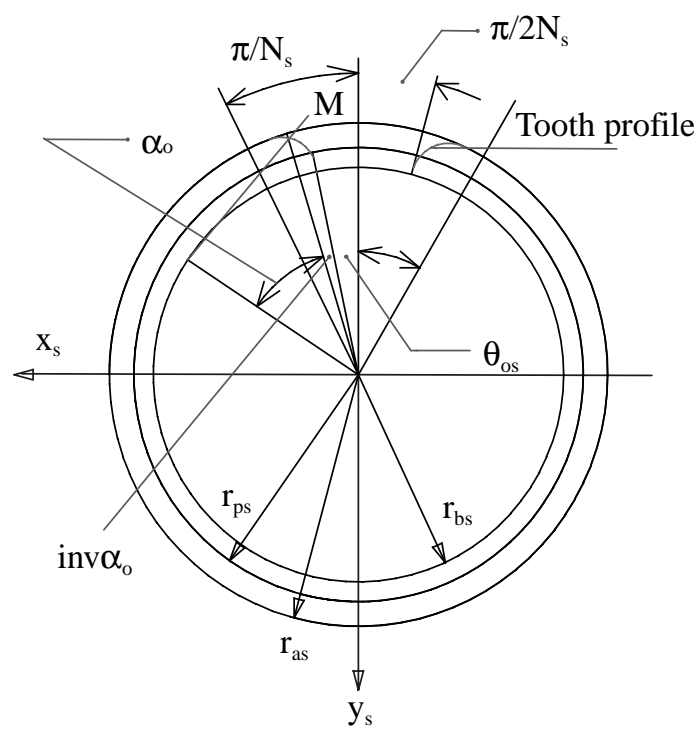

(b)

Fig. 1. (a) Face-gear generation process; (b) Shaper coordinate system.

$$
\theta_{o s}=\frac{\pi}{2 N_{s}}-i n v \alpha_{o}
$$

where $N_{s}$ and $\alpha_{o}$ denote tooth number and pressure angle of the shaper respectively, and inv is the involute function. The unit normal $\mathbf{n}_{\mathbf{s}}$ to the shaper surface is given by

$$
\mathbf{n}_{\mathbf{s}}=\frac{\frac{\partial \mathbf{r}_{s}}{\partial \theta_{s}} \times \frac{\partial \mathbf{r}_{s}}{\partial u_{s}}}{\left|\frac{\partial \mathbf{r}_{s}}{\partial \theta_{s}} \times \frac{\partial \mathbf{r}_{s}}{\partial u_{s}}\right|}=-\left[\begin{array}{c}
\cos \left(\theta_{o s}+\theta_{s}\right) \\
\sin \left(\theta_{o s}+\theta_{s}\right) \\
0
\end{array}\right]
$$

The face-gear tooth surface, $\Sigma_{2}$, is represented in coordinate system $S_{2}$ by the following matrix equation

$$
\mathbf{r}_{2}\left(u_{s}, \theta_{s}, \varphi_{s}\right)=M_{2 s}\left(\varphi_{s}\right) \mathbf{r}_{\mathbf{s}}\left(u_{s}, \theta_{s}\right)
$$

where $M_{2 s}$ is the homogeneous transformation matrix from coordinate system $S_{s}$ to $S_{2}$ by

$$
M_{2 s}=M_{2 t} M_{t m} M_{m}
$$

and where

$$
\begin{aligned}
M_{m s} & =\left[\begin{array}{cccc}
\cos \varphi_{s} & -\sin \varphi_{s} & 0 & 0 \\
\sin \varphi_{s} & \cos \varphi_{s} & 0 & 0 \\
0 & 0 & 1 & 0 \\
0 & 0 & 0 & 1
\end{array}\right] \\
M_{t m} & =\left[\begin{array}{cccc}
1 & 0 & 0 & 0 \\
0 & \cos \gamma_{m} & -\sin \gamma_{m} & 0 \\
0 & \sin \gamma_{m} & \cos \gamma_{m} & 0 \\
0 & 0 & 0 & 1
\end{array}\right] \\
M_{2 t} & =\left[\begin{array}{cccc}
\cos \varphi_{2 t} & \sin \varphi_{2 t} & 0 & 0 \\
-\sin \varphi_{2 t} & \cos \varphi_{2 t} & 0 & 0 \\
0 & 0 & 1 & 0 \\
0 & 0 & 0 & 1
\end{array}\right]
\end{aligned}
$$

$M_{m s}, M_{t m}$ and $M_{2 t}$ are the coordinate transformation matrices from $S_{s}$ to $S_{m}, S_{m}$ to $S_{t}$ and $S_{t}$ to $S_{2}$, respectively, as shown in Figures 2(a) and 2(b) and Table 1. In Figure 2(b), the auxiliary coordinate system, $S_{t}\left(x_{t}, y_{t}, z_{t}\right)$, is set up to simplify the coordinate transformation. Angle between axes $z_{m}$ and $z_{2}$ is determined by $\gamma_{m}=180-\gamma$, where $\gamma$ is the shaft angle of the face-gear. Rotation angles of the face-gear, $\varphi_{2 t}$, and the shaper, $\varphi_{s}$, are related by

$$
\varphi_{2 t}=\varphi_{s} \frac{N_{s}}{N_{2}}
$$

where $N_{2}$ denotes the tooth number of face-gear. The 
equation of meshing is represented as following [3]

$$
\begin{aligned}
& \mathbf{n}_{\mathbf{s}} \cdot \mathbf{v}_{\mathbf{s}}^{(s 2)}=f\left(u_{s}, \theta_{s}, \varphi_{s}\right)=0 \\
& \mathbf{v}_{\mathbf{s}}^{(s 2)}=\left(\omega_{s}^{(s)}-\omega_{s}^{(2)} \times \mathbf{r}_{\mathbf{s}}\right.
\end{aligned}
$$

where $\mathbf{v}_{\mathbf{s}}^{(s 2)}, \omega_{s}^{(s)}$ and $\omega_{s}^{(2)}$ denote respectively the sliding velocity between shaper and face-gear, angular velocities of shaper and face-gear in coordinate system, $S_{s}$. The face-gear surface in equation (4) is represented in term of $\theta_{\mathrm{s}}, \varphi_{\mathrm{s}}$ and $u_{\mathrm{s}}$. By relating equations (4), (7) and (7.a), parameter, $u_{\mathrm{s}}$, can be eliminated and the surface, $\Sigma_{2}$, can be represented by the vector function, $\mathbf{r}_{2}^{\prime}\left(\theta_{\mathrm{s}}, \varphi_{\mathrm{s}}\right)$.

\section{Kinematics of face-gear meshing with spur pinion}

The tooth surfaces are represented by $\Sigma_{i}, i=1$ for pinion and $i=2$ for face-gear. In the computer simulation, it is assumed that there exist misalignments of crossed and angular displacements between two rotating axes of the mating gears, and assembly error along the axis of

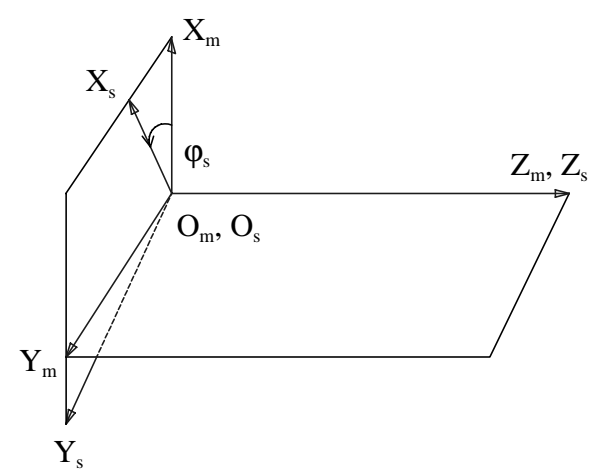

(a)

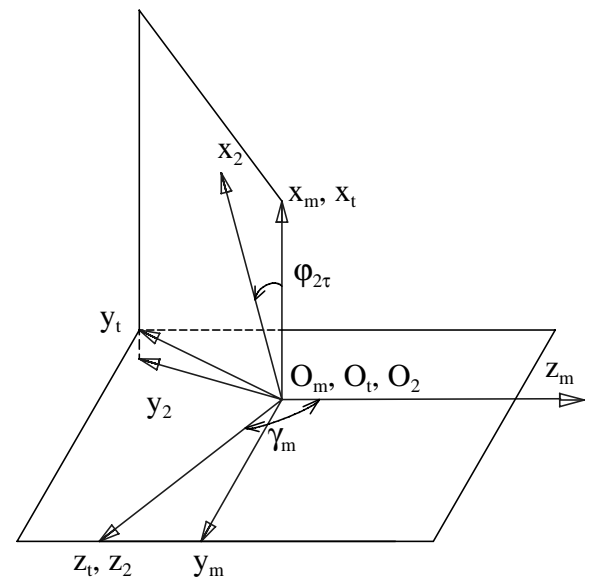

(b)

Fig. 2. (a) Coordinate systems $S_{s}$ and $S_{m}$ applied for generation; (b) Coordinate systems $S_{m}, S_{2}$ and $S_{t}$ applied for generation. face-gear direction.

Coordinate systems, $S_{1}\left(x_{1}, y_{1}, z_{1}\right)$ and $S_{f}\left(x_{f}, y_{f}, z_{f}\right)$, are fixed on the pinion and the frame of the face-gear drive respectively as shown in Figures 3(a) and 3(b). In

Table 1. Transformation of coordinate systems (+): clockwise, (-): counter-clockwise

\begin{tabular}{ccccc}
\hline $\begin{array}{c}\text { From coord. } \\
\text { system }\end{array}$ & \multicolumn{2}{c}{ Rotation } & Translation & To coord. \\
Axis & Angle & disp. & system \\
\hline$S_{s}$ & $z_{s}$ & $\varphi_{\mathrm{s}}(-)$ & & $S_{m}$ \\
$S_{m}$ & $x_{m}$ & $\gamma_{m}(+)$ & & $S_{t}$ \\
$S_{t}$ & $z_{t}$ & $\varphi_{2 t}(-)$ & & $S_{2}$ \\
$S_{2}$ & $z_{2}$ & $\varphi_{2}(-)$ & & $S_{c}$ \\
$S_{c}$ & $z_{c}$ & & $\Delta p$ & $S_{b}$ \\
$S_{b}$ & $x_{b}$ & $\gamma_{f}(-)$ & & $S_{a}$ \\
$S_{a}$ & $x_{a}$ & & $D$ & \\
$S_{a}$ & $y_{a}$ & & $\Delta E$ & \\
$S_{a}$ & $z_{a}$ & & $-\mathrm{Dcot} \gamma$ & $S_{f}$ \\
$S_{1}$ & $\mathrm{z}_{1}$ & $\varphi_{1}(-)$ & & $S_{f}$ \\
\hline
\end{tabular}

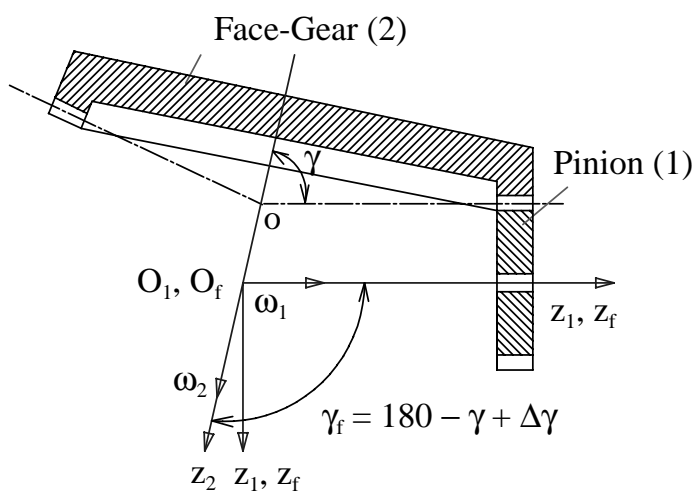

(a)

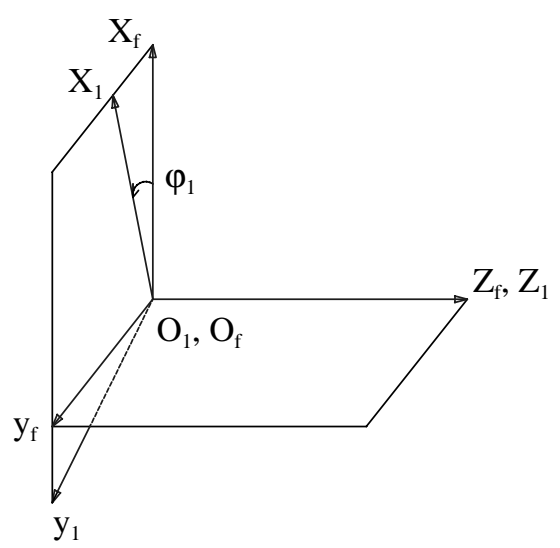

(b)

Fig. 3. (a) Pinion meshing with face-gear; (b) Coordinate systems $S_{1}$ and $S_{f}$ applied for simulation of meshing. 
order to simulate the misalignment of the face-gear, auxiliary coordinate systems, $S_{a}\left(x_{a}, y_{a}, z_{a}\right), S_{b}\left(x_{b}, y_{b}, z_{b}\right)$ and $S_{c}\left(x_{c}, y_{c}, z_{c}\right)$, are set up in Figure 4(a). The location of $\mathrm{Sa}$ with respect to $S_{f}$ is shown in Figure 4(b). Parameters, $\triangle E, D$ and $D \cot \gamma$, determine the location of the origin $O_{a}$ with respect to $O_{f}$, where $\Delta E$ is the shortest distance between the pinion and the face-gear axes when the axes are crossed but not intersected. In the following analysis, $\Delta E$ is used to simulate the crossed misalignment of the axes.

The face-gear performs rotation about axis $z_{2}$ as shown in Figures 4(c) and 4(d). The variable, $\Delta p$, along the axis of face-gear as shown in Figures 4(a) and 4(d) represents the assembly error of $S_{c}$ with respect to $S_{b}$. The crossed angle, $\gamma_{f}=180-\gamma+\Delta \gamma$, is used to simulate the angular misalignment of $S_{b}$ with respect to $S_{a}$ and $\Delta \gamma$ is caused by the angular misalignment.

According to Figure 3(a) and Table 1, the equations of the pinion tooth surface and its unit normal can be represented in the fixed coordinate system, $S_{f}$, by applying the following coordinate transformation matrix equations:

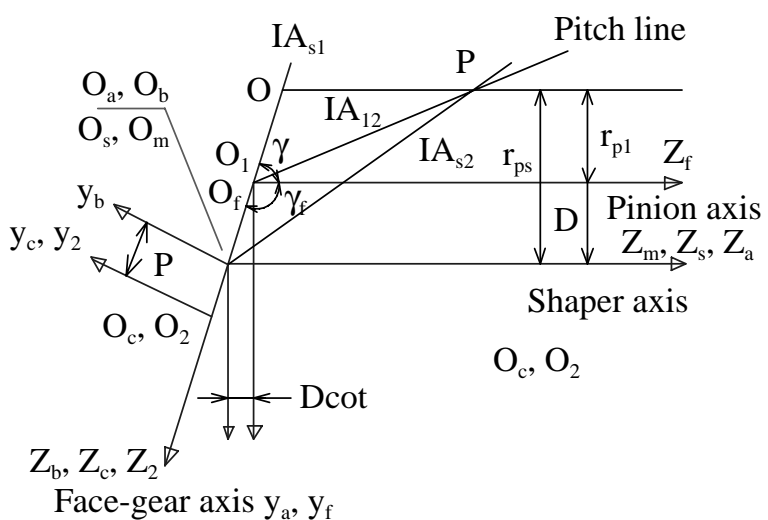

(a)

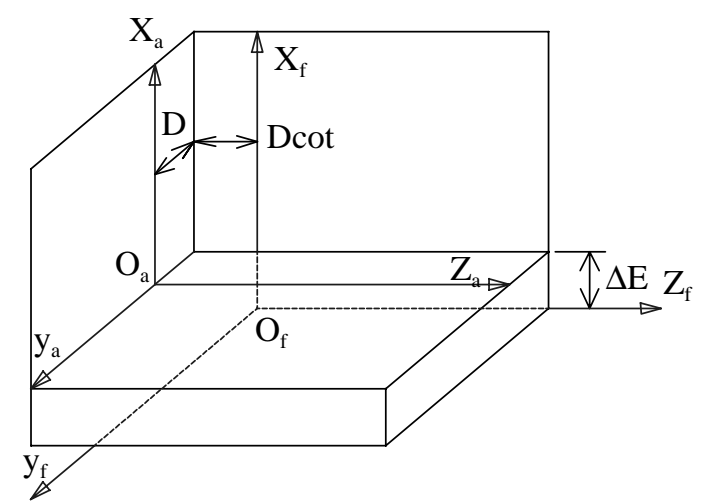

(b)

$$
\mathbf{R}_{\mathbf{f}}^{(1)}=M_{f 1} \mathbf{r}_{1}
$$

where

$$
\mathbf{r}_{1}(u, \theta)=\left[\begin{array}{c}
r_{b}\left[\sin \left(\theta_{0}+\theta\right)-\theta \cos \left(\theta_{0}+\theta\right)\right] \\
-r_{b}\left[\cos \left(\theta_{0}+\theta\right)+\theta \sin \left(\theta_{0}+\theta\right)\right] \\
u \\
1
\end{array}\right]
$$

$$
M_{f 1}=\left[\begin{array}{cccc}
\cos \varphi_{1} & \sin \varphi_{1} & 0 & 0 \\
-\sin \varphi_{1} & \cos \varphi_{1} & 0 & 0 \\
0 & 0 & 1 & 0 \\
0 & 0 & 0 & 1
\end{array}\right]
$$

and

$$
\mathbf{n}_{\mathbf{f}}^{(1)}=L_{f 1} \mathbf{n}_{1}
$$

and where

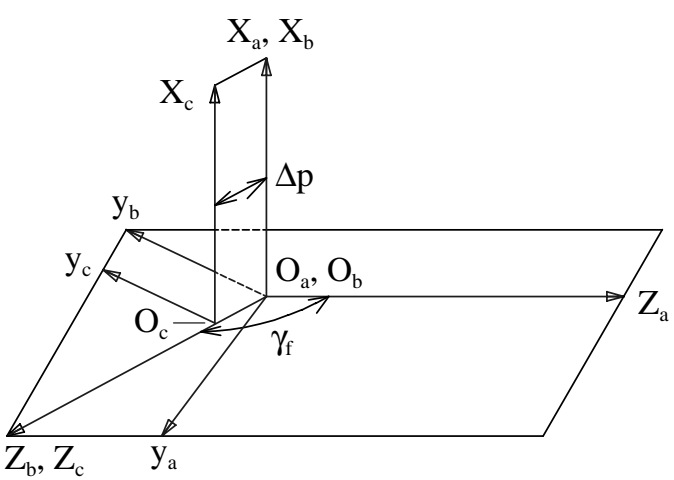

(c)

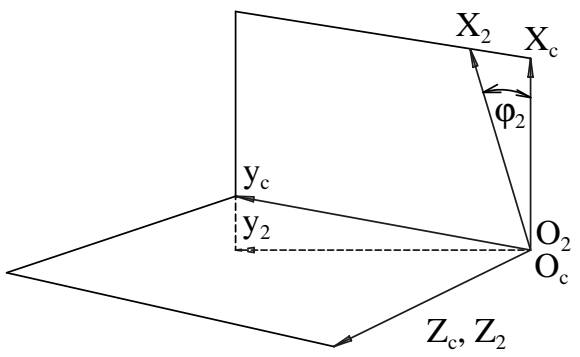

(d)

Fig. 4. (a) Relationship of coordinate systems of shaper, pinion and face-gear; (b) Coordinate systems $S_{a}$ and $S_{f}$ applied for simulation of meshing; (c) Coordinate systems $S_{a}, S_{b}$ and $S_{c}$ applied for simulation of meshing; (d) Coordinate systems $S_{c}$ and $S_{2}$ applied for simulation of meshing. 


$$
\begin{aligned}
& \mathbf{n}_{\mathbf{1}}=\frac{\frac{\partial \mathbf{r}_{1}}{\partial \theta_{s}} \times \frac{\partial \mathbf{r}_{1}}{\partial u_{s}}}{\left|\frac{\partial \mathbf{r}_{1}}{\partial \theta_{s}} \times \frac{\partial \mathbf{r}_{1}}{\partial u_{s}}\right|}=-\left[\begin{array}{c}
\cos \left(\theta_{o}+\theta\right) \\
\sin \left(\theta_{o}+\theta\right) \\
0
\end{array}\right] \\
& L_{f 1}=\left[\begin{array}{ccc}
\cos \varphi_{1} & \sin \varphi_{1} & 0 \\
-\sin \varphi_{1} & \cos \varphi_{1} & 0 \\
0 & 0 & 1
\end{array}\right]
\end{aligned}
$$

Where $M_{f 1}$ and $L_{f 1}$ are the homogeneous transformation matrix and the transformation matrix from coordinate system $S_{1}$ to $S_{f}$ respectively, $\mathbf{r}_{\mathbf{1}}$ and $\mathbf{n}_{\mathbf{1}}$ are the position vectors of pinion surface and unit normal to the surface respectively.

According to Figures 4(a) and 4(d) and Table 1, the equations of the face-gear tooth surface and its unit normal can be represented in the fixed coordinate system, $S_{f}$, by

$$
\mathbf{R}_{\mathbf{f}}^{(2)}=M_{f 2} M_{2 s} \mathbf{r}_{\mathbf{s}}
$$

where

$$
M_{f 2}=M_{f a} M_{a b} M_{b c} M_{c 2}
$$

$$
M_{c 2}=\left[\begin{array}{cccc}
\cos \varphi_{2} & -\sin \varphi_{2} & 0 & 0 \\
\sin \varphi_{2} & \cos \varphi_{2} & 0 & 0 \\
0 & 0 & 1 & 0 \\
0 & 0 & 0 & 1
\end{array}\right]
$$$$
M_{b c}=\left[\begin{array}{cccc}
1 & 0 & 0 & 0 \\
0 & 1 & 0 & 0 \\
0 & 0 & 1 & \Delta p \\
0 & 0 & 0 & 1
\end{array}\right]
$$

$$
M_{a b}=\left[\begin{array}{cccc}
1 & 0 & 0 & 0 \\
0 & \cos \gamma_{f} & -\sin \gamma_{f} & 0 \\
0 & \sin \gamma_{f} & \cos \gamma_{f} & 0 \\
0 & 0 & 0 & 1
\end{array}\right]
$$

$$
M_{f a}=\left[\begin{array}{cccc}
1 & 0 & 0 & D \\
0 & 1 & 0 & \Delta E \\
0 & 0 & 1 & -D \cot \gamma \\
0 & 0 & 0 & 1
\end{array}\right]
$$

and

$$
\mathbf{n}_{\mathbf{f}}^{(2)}=L_{f 2} L_{2 s} \mathbf{n}_{\mathbf{s}}
$$

and where

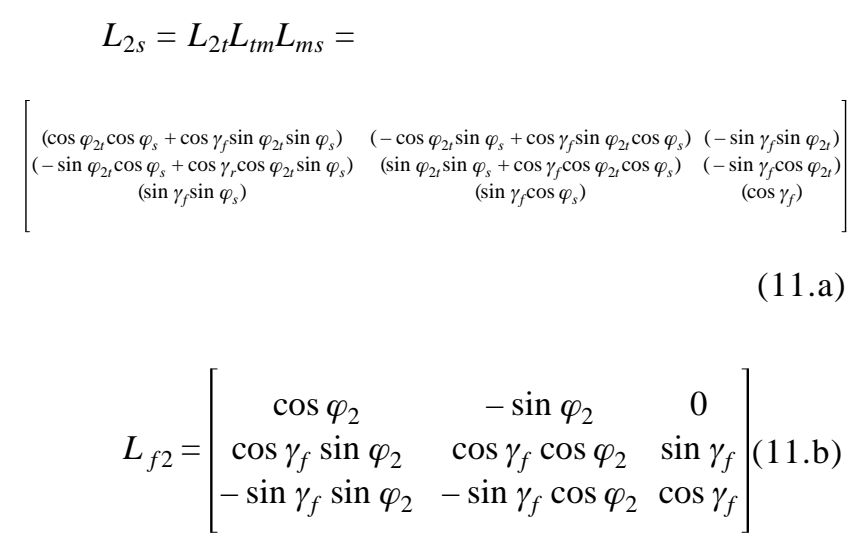

where $M_{f 2}$ and $L_{f 2}$ are the homogeneous transformation matrix and the transformation matrix from coordinate system $S_{2}$ to $S_{f}$ respectively, and $L_{2 s}$ is the transformation matrix from coordinate system $S_{s}$ to $S_{2}$.

\section{Tooth contact analysis}

In the generation process, the surfaces of the teeth of the face-gear and the shaper are in line contact at any instant. When the pinion of the face-gear drive is identical to the shaper, the generated face-gear drive becomes sensitive to misalignment. Therefore, it is necessary to provide an instantaneous point contact between the tooth surfaces of the pinion and face-gear instead of a line contact. Therefore, the face-gear drive will be less sensitive to misalignment [9].

In Figure 4(a), IA $A_{s 2}, I A_{s 1}$ and $I A_{12}$ denote respectively the instantaneous axes of rotation during meshing between $\Sigma_{s}$ and $\Sigma_{2}, \Sigma_{s}$ and $\Sigma_{1}, \Sigma_{1}$ and $\Sigma_{2}$. Surfaces, $\Sigma_{s}$ and $\Sigma_{2}$, are in line contact at any instant in the generation process of the face-gear by the shaper. In the imaginary meshing process of the shaper and the pinion, surfaces, $\Sigma_{s}$ and $\Sigma_{2}$, are in line contact at any instant. The tooth number of the shaper is usually chosen not equal but larger than the tooth number of pinion. Hence, the pinion tooth surface, $\Sigma_{1}$, and the generated face-gear tooth surface, $\Sigma_{2}$, become point contact at every instant due to the different pitch cone angles of shaper and pinion.

In order to perform the tooth contact analysis (TCA), the equations of face-gear and pinion tooth surfaces should be represented in the coordinate system $S_{f}$. At the point of contact, due to the tangency of the two gear tooth surfaces, the position vectors and their unit normals of both the face-gear and pinion tooth surfaces should be the same. Therefore, the following equations can be obtained [3]:

$$
\mathbf{R}_{\mathbf{f}}^{(1)}=\mathbf{R}_{\mathbf{f}}^{(2)}
$$




$$
\mathbf{n}_{\mathbf{f}}^{(1)}=\mathbf{n}_{\mathbf{f}}^{(2)}
$$

If equations (12) and (13) are considered simultaneously, with these equations, one has a system of five independent equations with six unknowns: $\varphi_{2}, \varphi_{1}, \theta, u, \theta_{s}$ and $\varphi_{s}$, and with an additional relationship of $\left|\mathbf{n}_{\mathbf{f}}^{(1)}\right|=\left|\mathbf{n}_{\mathbf{f}}{ }^{(2)}\right|=1$. Symbols $\varphi_{2}$ and $\varphi_{1}$ denote the rotation angles of facegear and pinion, respectively. To solve the system of equations, one of the unknowns, $\varphi_{2}$ may be considered as input variable to solve the five independent equations with six unknowns.

We chose $\varphi_{2}$ as an input variable in the practical operation, then the output rotation angle is $\varphi_{1}$. However, for the ideal gear meshing, the output rotation angle, $\varphi_{1}$, is equal to the product of input rotation angle, $\varphi_{2}$, and the gear ratio, $N_{1} / N_{2}$, that is, $\varphi_{1}=\varphi_{2} N_{1} / N_{2}$, where $N_{1}$ and $N_{2}$ represent the number of teeth of pinion and facegear, respectively. From the above derivation, the relation of $\varphi_{1}$ and $\varphi_{2}$ is a nonlinear function for the practical case. The kinematic error of the gear train can be expressed as

$$
\Delta \varphi_{1}=\varphi_{1}-\varphi_{2} N_{1} / N_{2}
$$

where $\Delta \varphi_{1}$ represents the kinematic error of the gear train as a function of input variable, $\varphi_{2}$.

\section{NUMERICAL RESULTS AND DISCUSSION}

The analysis of contact path and kinematic error of face-gear drives is presented in this section. Some

Table 2. Some important parameters chosen for the face-gear, spur pinion and shaper

\begin{tabular}{lccc}
\hline Items & Face-gear & Pinion & Shaper \\
\hline Number of teeth & 107 & 28 & 31 \\
Pressure angle & $25^{\circ}$ & $25^{\circ}$ & $25^{\circ}$ \\
Pitch cone angle & $160^{\circ}$ & none & none \\
Module $(\mathrm{mm})$ & 3.175 & 3.175 & 3.175 \\
\hline
\end{tabular}

important parameters of spur pinion, face-gear and shaper chosen for this numerical example are listed in Table 2. The analysis will be limited to the case of face-gear drives with intersecting axes of rotation. Numerical examples are given below to illustrate the effects of various condition of meshing on the contact path and kinematic error.

In Table 3, we consider the dislocation of bearing contact for aligned face-gear drive with intersecting axes and for misalignment of $\Delta E=0.1 \mathrm{~mm}$ between axes of face-gear and pinion. The effect of positive value of $\Delta E$ is to bring the contact points closer to the inner radius and the root of the face-gear. It leads to the less torque driving upon the gear sets and the larger load capacity for the face-gear.

The dislocated bearing contacts of axial displacement, $\Delta p$, along the axis of face-gear direction and angular misalignment, $\Delta \gamma$, of the axis of face-gear are shown in Table 4 . The effects of positive $\Delta p$ and $\Delta \gamma$ have opposite effect on the influence to that of positive $\Delta E$. It results in a larger torque on the gear sets and more bending for the teeth of the face-gear.

The kinematic errors due to misalignment $\Delta E$ at the levels of $0,0.1,0.2$ and $0.3 \mathrm{~mm}$ between axes of pinion and face-gear versus input rotation angle are shown in Figure 5. In this particular gear meshing, the

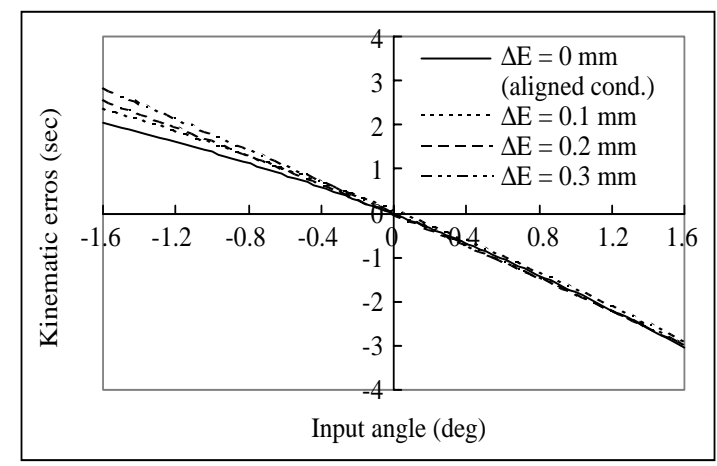

Fig. 5. The effect of the variation of the shortest distance between facegear and pinion axes upon kinematic error.

Table 3. Contact path of ideal case and $\Delta E=0.1 \mathrm{~mm}$

\begin{tabular}{ccccccc}
\hline Diff. case & \multicolumn{3}{c}{ Ideal case } & \multicolumn{3}{c}{$\Delta E=0.1 \mathrm{~mm}$} \\
\hline$\phi_{2}(\mathrm{deg})$ & $x_{f}(\mathrm{~mm})$ & $y_{f}(\mathrm{~mm})$ & $z_{f}(\mathrm{~mm})$ & $x_{f}(\mathrm{~mm})$ & $y_{f}(\mathrm{~mm})$ & $z_{f}(\mathrm{~mm})$ \\
1.5 & 5.49 & -42.506 & 192.463 & 5.516 & -42.299 & 188.249 \\
1.0 & 4.182 & -42.986 & 199.625 & 4.199 & -42.755 & 194.62 \\
0.5 & 2.874 & -43.467 & 208.256 & 2.881 & -43.207 & 202.191 \\
0 & 1.565 & -43.947 & 218.529 & 1.563 & -43.659 & 211.278 \\
-0.5 & 0.256 & -44.424 & 230.796 & 0.245 & -44.111 & 222.16 \\
-1.0 & -1.053 & -44.901 & 245.588 & -1.074 & -44.564 & 235.229 \\
-1.5 & -2.363 & -45.378 & 263.496 & -2.393 & -45.013 & 250.895 \\
\hline
\end{tabular}


Table 4. Contact path of $\Delta p=0.1 \mathrm{~mm}$ and $\Delta \gamma=0.01 \mathrm{deg}$

\begin{tabular}{ccclccc}
\hline Diff. case & \multicolumn{3}{c}{$\Delta p=0.1 \mathrm{~mm}$} & \multicolumn{3}{c}{$\Delta \gamma=0.01 \mathrm{deg}$} \\
\hline$\phi_{2}(\mathrm{deg})$ & $x_{f}(\mathrm{~mm})$ & $y_{f}(\mathrm{~mm})$ & $z_{f}(\mathrm{~mm})$ & $x_{f}(\mathrm{~mm})$ & $y_{f}(\mathrm{~mm})$ & $z_{f}(\mathrm{~mm})$ \\
1.5 & 5.727 & -43.003 & 204.809 & 5.579 & -42.709 & 197.287 \\
1.0 & 4.446 & -43.55 & 214.435 & 4.285 & -43.227 & 205.656 \\
0.5 & 3.163 & -44.095 & 225.881 & 2.994 & -43.75 & 215.791 \\
0 & 1.88 & -44.64 & 239.656 & 1.704 & -44.279 & 228.11 \\
-0.5 & 0.598 & -45.185 & 256.341 & 0.417 & -44.812 & 243.084 \\
-1.0 & -0.685 & -45.728 & 276.611 & -0.866 & -45.356 & 261.671 \\
-1.5 & -1.969 & -46.27 & 301.663 & -2.144 & -45.914 & 285.088 \\
\hline
\end{tabular}

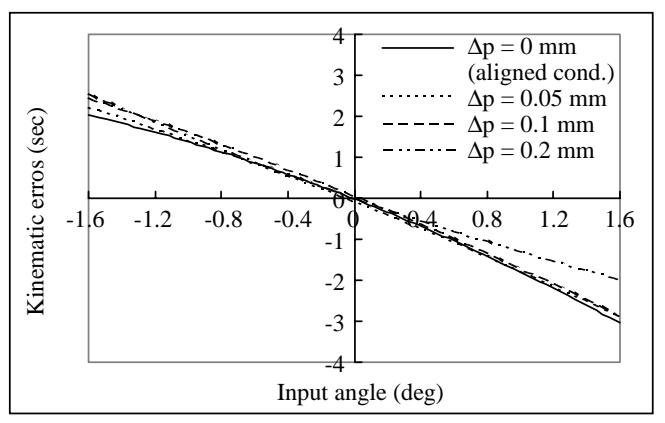

Fig. 6. The effect of assembly error along the direction of rotation axis of face-gear upon kinematic error.

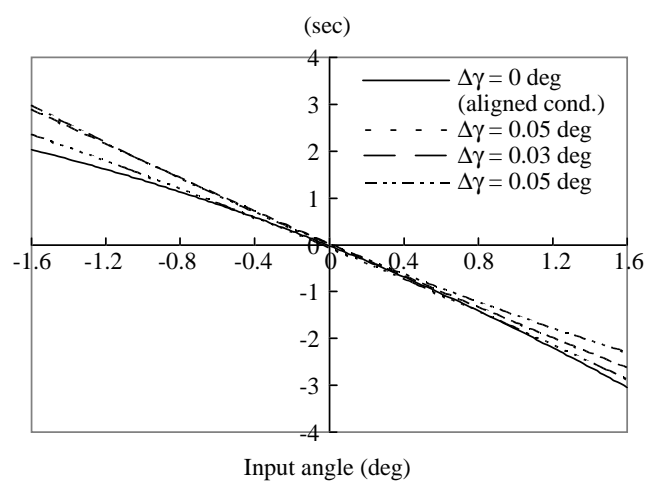

Fig. 7. The effect of angular misalignment upon kinematic error.

pinion and face-gear will contact at input angle, $\varphi_{2}$, from 1.6 degrees to -1.6 degrees. In the negative rotation part ( 0 to -1.6 degrees), larger misalignment $\Delta E$ leads to larger kinematic error. In the positive rotation part (1.6 to 0 degrees), kinematic error is relatively insensitive to misalignment.

The kinematic errors due to misalignment $\Delta p$ at the levels of $0,0.05,0.1$ and $0.2 \mathrm{~mm}$ along the rotation axis of the face-gear direction versus input rotation angle are shown in Figure 6. In the negative rotation part, larger

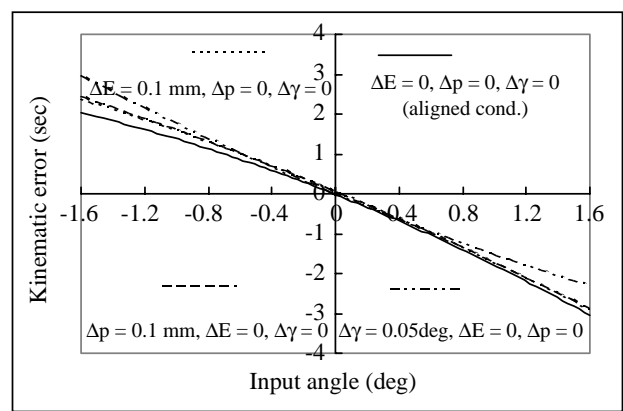

Fig. 8. The effect of angular misalignment upon kinematic error.

misalignment, $\Delta p$, leads to larger kinematic error. In the positive rotation part, there is less effect on kinematic error due to larger value of $\Delta p$.

The kinematic errors due to angular misalignment, $\Delta \gamma$, at the levels of $0,0.01,0.03$ and 0.05 degrees versus input rotation angle are shown in Figure 7 . In the negative rotation part, larger misalignment, $\Delta \gamma$, leads to larger kinematic error. In the positive rotation part, larger assembly error leads to smaller kinematic error.

The kinematic errors due to different types of misalignment such as $\Delta E, \Delta p$ and $\Delta \gamma$ versus input rotation angle are shown in Figure 8. Approximately the same order of kinematic error due to misalignment is found.

\section{CONCLUSION}

From the numerical examples discussed above, some important characteristics of this type of face-gear drive can be summarized as follows:

(1) Surfaces of pinion and face-gear are in point contact in this type of face-gear drive at any instant, provided that the pinion is not identical to the shaper.

(2) The effect of positive $\Delta E$ leads to a smaller torque driving upon the gear sets and a larger load capacity 
for the face-gear. The effect of positive $\Delta p$ or $\Delta \gamma$ just shows the opposite behavior.

(3) Kinematic error is insensitive to the assembly error along the direction of rotation axis of face-gear, misalignment of crossed and angular displacement between axes of spur pinion and face-gear in this type of face-gear drive.

\section{NOMENCLATURE}

$D \quad$ Shortest distance between the axes of $x_{a}$ and $z_{f}$ in coordinate systems of $S_{a}$ and $S_{f}$.

K.E. Kinematic error.

$L_{i j} \quad$ Transformation matrices which transform the vector from coordinate system $S_{j}$ to $S_{i}$.

$M_{i j} \quad$ Homogeneous transformation matrices which transform the vector from coordinate system $S_{j}$ to $S_{i}$.

$N_{i} \quad$ Number of teeth of shaper, pinion and face-gear for $i=s, 1,2$.

$n_{f}(\mathrm{i})$ Unit normal of the pinion and face-gear tooth surfaces represented in the coordinate system $S_{i}(i=1,2)$.

$\mathbf{R}_{\mathbf{f}}{ }^{(i)}$ Position vector of the pinion, face-gear tooth surface represented in the corresponding coordinate system $S_{i}(i=1,2, f)$.

$r_{a s} \quad$ Addendum circle radius of the shaper.

$r_{b s} \quad$ Base circle radius of the shaper.

$r_{p 1} \quad$ Pitch circle radius of the pinion.

$r_{p s} \quad$ Pitch circle radius of the shaper.

$\mathbf{R}_{\mathbf{i}} \quad$ Position vectors of the shaper, pinion and facegear for $\mathbf{i}=\mathbf{s}, \mathbf{1}$ and $\mathbf{2}$ in terms of variables, $u_{s}$, $\theta_{s}$ and $\varphi_{s}$.

$\mathbf{r}_{2}{ }^{\prime}$ Position vectors of the face-gear in terms of variables, $\theta_{s}$ and $\varphi_{s}$.

$S_{i} \quad$ Coordinate system $S(i=1,2, a, b, c, f, m, s, t)$.

$u \quad$ Gaussian coordinate of $\Sigma_{1}$.

$u_{s} \quad$ Gaussian coordinate of $\Sigma_{s}$.

$\mathbf{v}_{\mathbf{s}}{ }^{(s 2)}$ Sliding velocity between shaper and face-gear.

$\alpha_{o} \quad$ Pressure angle.

$\Delta E$ Shortest distance between the pinion and the face-gear axes.

$\Delta \gamma \quad$ Angular misalignment of the face-gear.

$\Delta p \quad$ Axial displacement of the face-gear.

$\varphi_{i} \quad$ Rotation angle of shaper, pinion and face-gear for $i=s, 1,2$.

$\theta \quad$ Gaussian coordinate of $\Sigma_{1}$.

$\theta_{s} \quad$ Gaussian coordinate of $\Sigma_{s}$. $\gamma_{f} \quad$ Half-cone angle of face-gear including angular misalignment.

$\gamma_{m} \quad$ Half-cone angle of face-gear.

$S_{i} \quad$ Tooth surface of pinion, face-gear and $\operatorname{shaper}(i=$ $1,2, s)$.

$\omega_{i} \quad$ Rotation speed of shaper, pinion and face-gear $(i$ $=s$,

\section{REFERENCES}

1. Buckingham, E., Analytical Mechanics of Gears, Dover Publications, Inc., New York (1949).

2. Dudley, D.W., Gear Handbook the Design, Manufacture, and Application of Gears. McGraw-Hill, New York (1962).

3. Litvin, F.L., Theory of Gearing (PR 1212), NASA, Washington, DC (1989).

4. Litvin, F.L., Gear Geometry and Applied Theory, Prentice-Hall, Inc., Englewood Cliffs, NJ (1994).

5. Litvin, F.L. and Egelja, A., "Computerized Design, Generation and Simulation of Meshing of Orthogonal Offset Face-Gear Drive with a Spur Involute Pinion with Localized Bearing Contact," Mech. Mach. Theory, Vol. 33, pp. 87-102 (1998).

6. Litvin, F.L., Fuentes, A., and Howkins, M., "Design, Generation, and TCA of new type of Asymmetric FaceGear Drive with Modified Geometry," Comput. Method Appl. M., Vol. 190, pp. 5837-5865 (2001).

7. Litvin, F.L., Fuentes, A., Zanzi, C., and Pontiggia, M., "Design, Generation, and Stress Analysis of Two Versions of Geometry of Face-Gear Drives," Mech. Mach. Theory, Vol. 37, pp. 1179-1211 (2002).

8. Litvin, F.L., Fuentes, A., Zanzi, C., Pontiggia, M., and Handschuh, R.F., "Face-Gear Drive with Spur Involute pinion: Geometry, Generation by a Worm, Stress Analysis," Comput. Method Appl. M., Vol. 191, pp. 2785-2813 (2002).

9. Litvin, F.L., Zhang, Y., Wang, J.C., Bossler, R.B., and Chen, J.D., "Design and Geometry of Face-Gear Drives," ASME Trans. J. Mech. Design, Vol. 114, pp. 642-647 (1992).

10. Litvin, F.L., Wang, J.C., Bossler, R.B., Chen, J.D., Heath, G., and Lewicki, D.G., "Application of FaceGear Drives in Helicopter Transmissions," Proc. International Power Transmission and Gearing Conference, ASME, Vol. 1, pp. 267-274 (1992). 